Article

\title{
Asymptotic and Oscillatory Properties of Noncanonical Delay Differential Equations
}

\author{
Osama Moaaz ${ }^{1,2, *}$, Clemente Cesarano ${ }^{2, *}$ and Sameh Askar ${ }^{3}$ \\ 1 Department of Mathematics, Faculty of Science, Mansoura University, Mansoura 35516, Egypt \\ 2 Section of Mathematics, International Telematic University Uninettuno, Corso Vittorio Emanuele II, 39, \\ 00186 Roma, Italy \\ 3 Department of Statistics and Operations Research, College of Science, King Saud University, P.O. Box 2455, \\ Riyadh 11451, Saudi Arabia; saskar@ksu.edu.sa or s.e.a.askar@hotmail.co.uk \\ * Correspondence: o_moaaz@mans.edu.eg (O.M.); c.cesarano@uninettunouniversity.net (C.C.)
}

check for updates

Citation: Moaaz, O.; Cesarano, C.; Askar, S. Asymptotic and Oscillatory Properties of Noncanonical Delay Differential Equations. Fractal Fract. 2021, 5, 259. https://doi.org/ 10.3390 / fractalfract5040259

Academic Editor: Hari Mohan Srivastava

Received: 27 October 2021 Accepted: 25 November 2021 Published: 6 December 2021

Publisher's Note: MDPI stays neutral with regard to jurisdictional claims in published maps and institutional affiliations.

Copyright: (c) 2021 by the authors. Licensee MDPI, Basel, Switzerland. This article is an open access article distributed under the terms and conditions of the Creative Commons Attribution (CC BY) license (https:// creativecommons.org/licenses/by/ $4.0 /)$.

\begin{abstract}
In this work, by establishing new asymptotic properties of non-oscillatory solutions of the even-order delay differential equation, we obtain new criteria for oscillation. The new criteria provide better results when determining the values of coefficients that correspond to oscillatory solutions. To explain the significance of our results, we apply them to delay differential equation of Euler-type.
\end{abstract}

Keywords: delay differential equation; oscillation; noncanonical case

\section{Introduction}

This work is devoted to study and discussion of the oscillatory behavior of solutions of the even-order delay differential equations (DDEs)

$$
\left(c(s) u^{(n-1)}(s)\right)^{\prime}+p(s) u(\theta(s))=0, s \geq s_{0},
$$

under the hypotheses:

Hypothesis $\mathbf{1}(\mathrm{H} 1) . n \geq 4$ is an even integer;

Hypothesis $2(\mathrm{H} 2) . c, p \in C\left(\left[s_{0}, \infty\right)\right), c(s)>0, c^{\prime}(s) \geq 0, p(s) \geq 0$, and

$$
\int_{s_{0}}^{\infty} c^{-1}(\xi) \mathrm{d} \xi<\infty
$$

Hypothesis $3(\mathrm{H} 3) . \theta \in C\left(\left[s_{0}, \infty\right)\right), \theta(s)<s, \theta^{\prime}(s) \geq 0$, and $\lim _{s \rightarrow \infty} \theta(s)=\infty$.

By a proper solution of (1), we mean a real-valued function $u \in C^{n-1}\left(\left[s_{0}, \infty\right)\right)$ with $c u^{(n-1)} \in C^{1}\left(\left[s_{0}, \infty\right)\right)$, and $\sup \{|u(\zeta)|: \zeta \geq s\}>0$, for $s \in\left[s_{0}, \infty\right)$, and $u$ satisfies (1) on $\left[s_{0}, \infty\right)$. A solution $u$ of $(1)$ is called non-oscillatory if it is eventually positive or eventually negative; otherwise, it is called oscillatory. The equation itself is termed oscillatory if all its solutions oscillate.

The interest in studying the qualitative properties of differential equations have been increasing in recent years due to several applications of such equations in different life sciences see [1-3]. Works [4-7] contributed to the development of the oscillation theory of second-order DDEs, and works [8-10] to the development of the oscillation theory of neutral DDEs.

Even-order differential equations are frequently experienced in mathematical models of different biological, physical, and chemical phenomena. Applications include, for example, issues of flexibility, deformity of constructions, or soil settlement; see [11]. 
Our interest in this work is focused on DDEs of the even-order, which has attracted the attention of researchers, for a follow-up to developments in the study the oscillation of even-order DDEs in the canonical case, see for example [12-14].

Baculíková et al. [15] studied the oscillatory properties of the DDE

$$
\left(c(s)\left(u^{(n-1)}(s)\right)^{\alpha}\right)^{\prime}+p(s) f(u(\theta(s)))=0,
$$

in the canonical case

$$
\int_{s_{0}}^{\infty} c^{-1 / \alpha}(\xi) \mathrm{d} \xi=\infty
$$

and the non-canonical case

$$
\int_{s_{0}}^{\infty} c^{-1 / \alpha}(\xi) \mathrm{d} \xi<\infty
$$

In the non-canonical case (4), they proved that if the first-order DDE

$$
v^{\prime}(s)+\frac{1}{c^{1 / \beta}(s)}\left(\int_{s_{0}}^{s} p(\xi)\left(\frac{\epsilon_{1} \theta^{n-2}(\xi)}{(n-2) !}\right)^{\beta} \mathrm{d} \xi\right)^{1 / \beta} v(\theta(s))=0
$$

is oscillatory for some $\epsilon_{1} \in(0,1)$, then there are no solutions to (3) that belong to the following class

$$
K:=\left\{u(s): u(s)>0, u^{\prime}(s)>0, u^{(n-2)}(s)>0 \text {, and } u^{(n-1)}(s)<0 \text {, eventually }\right\} .
$$

By Riccati substitution, Zhang et al. $[16,17]$ studied Equation (3) when $f(u):=u^{\alpha}$ where $\alpha$ is a quotient of odd positive integers, and created the criterion

$$
\limsup _{s \rightarrow \infty} \int_{s_{0}}^{s}\left(\left(\frac{\epsilon_{2} \theta^{n-2}(\xi)}{(n-2) !}\right)^{\beta} p(\xi)\left(\int_{\xi}^{\infty} c^{-1 / \beta}(z) \mathrm{d} z\right)^{\beta}-\frac{(\beta /(\beta+1))^{\beta+1}}{c^{1 / \beta}(\xi) \int_{\xi}^{\infty} c^{-1 / \beta}(z) \mathrm{d} z}\right) \mathrm{d} \xi=\infty .
$$

for some $\epsilon_{2} \in(0,1)$, to ensure that the class $K$ is empty. As an extension and complement to the results in [17], Moaaz et al. [18] recently used a generalized Riccati substitution to prove that if there is a $\rho \in C^{1}\left(\left[s_{0}, \infty\right), \mathbb{R}^{+}\right)$that satisfies

$$
\limsup _{s \rightarrow \infty} \frac{\left(\int_{s}^{\infty} c^{-1 / \beta}(z) \mathrm{d} z\right)^{\beta}}{\rho(s)} \int_{s_{0}}^{s}\left(\rho(\xi) p(\xi)\left(\frac{\epsilon_{3}}{2} \theta^{2}(\xi)\right)^{\beta}-\frac{c(\xi)\left(\rho^{\prime}(\xi)\right)^{\beta+1}}{(\beta+1)^{(\beta+1)} \rho^{\beta}(\xi)}\right) \mathrm{d} \xi>1,
$$

for some $\epsilon_{3} \in(0,1)$, then the class $K$ is empty.

On the other hand, the study of oscillation of odd-order differential equations has received great interest in the last two years, see for example [19-23]. The study of odd and even differential equations differs in that when studying odd differential equations, the different states of the derivatives of the positive solutions increase, which increases the restrictions imposed when testing the oscillation. Therefore, most of the works interested in studying the oscillation of delay differential equations focus only on one type, either even or odd differential equations.

In this paper, we derive new asymptotic properties of the solutions to Equation (1), which belong to class $K$. Then, we improve these properties by using approaches of an iterative nature. After that we get a new criterion that guarantees that there are no solutions in class $K$. Finally, we discuss the effect of this new criterion on the oscillatory properties of the solutions of (1).

The following lemmas are needed in the proofs of our main results. 
Lemma 1. ([24] (Lemma 2.2.3)) Suppose that $G \in C^{r}\left(\left[s_{0}, \infty\right),(0, \infty)\right), G^{(r)}(s)$ is of fixed sign for all $s \geq s_{1}$ for some $s_{1} \geq s_{0}, G^{(r)} \neq 0$ on a subray of $\left[s_{0}, \infty\right)$ and $\lim _{s \rightarrow \infty} G(s) \neq 0$. If $G^{(r-1)}(s) G^{(r)}(s) \leq 0$ for $s \in\left[s_{1}, \infty\right)$, then there is a $s_{\lambda} \geq s_{1}$ such that

$$
G(s) \geq \frac{\epsilon}{(r-1) !} s^{r-1}\left|G^{(r-1)}(s)\right|,
$$

for $\epsilon \in(0,1)$ and $s \in\left[s_{\lambda}, \infty\right)$.

\section{Main Results}

For brevity, we denote the set of all eventually positive solutions of (1) by $U^{*}$. Moreover, we define the operators $w_{k}$ by

$$
w_{0}(s):=\int_{s}^{\infty} c^{-1}(\xi) \mathrm{d} \xi, w_{k}(s):=\int_{s}^{\infty} w_{k-1}(\xi) \mathrm{d} \xi, \text { for } k=1,2, \ldots, n-2 .
$$

Lemma 2. Assume that $u \in U^{*}$ and satisfies

$$
u^{\prime}(s) \text { and } u^{(n-2)}(s) \text { are positive, and } u^{(n-1)}(s) \text { is negative for } s \geq s_{1} \in\left[s_{0}, \infty\right) \text {. }
$$

If

$$
\int_{s_{0}}^{\infty}\left(\frac{1}{c(z)} \int_{s_{2}}^{z} \theta^{n-2}(\xi) p(\xi) \mathrm{d} \xi\right) \mathrm{d} z=\infty
$$

then, for all $\epsilon_{0} \in(0,1)$,

$$
\begin{aligned}
& \left(c_{0,1}\right) u(s) \geq \frac{\epsilon_{0}}{(n-2) !} s^{n-2} u^{(n-2)}(s) \\
& \left(c_{0,2}\right) \lim _{s \rightarrow \infty} u^{(n-2)}(s)=0 \\
& \left(c_{0,3}\right) u^{(n-2)}(s) \geq-w_{0}(s) c(s) u^{(n-1)}(s) \text { and } \frac{\mathrm{d}}{\mathrm{d} s} \frac{u^{(n-2)}(s)}{w_{0}(s)}>0 .
\end{aligned}
$$

Proof. For $\left(c_{0,1}\right)$ : Using Lemma 1 with $G=u$ and $r=n-1$, we obtain that $\left(c_{0,1}\right)$ holds. For $\left(c_{0,2}\right)$ : From (1), we note that $c \cdot u^{(n-1)}$ is non-increasing. Since $u^{(n-2)} \eta$, we have that $\lim _{s \rightarrow \infty} u^{(n-2)}(s)=\varrho_{0} \geq 0$. If we suppose the contrary that $\varrho_{0}>0$, then there is a $s_{2} \geq s_{1}$ with $u^{(n-2)}(s) \geq \varrho_{0}$ for $s \geq s_{2}$, which with (1) and $\left(c_{0,1}\right)$ gives

$$
\begin{aligned}
\left(c(s) u^{(n-1)}(s)\right)^{\prime} & \leq-\epsilon_{0} \frac{\theta^{n-2}(s)}{(n-2) !} u^{(n-2)}(s) p(s) \\
& \leq-\frac{\epsilon_{0} \varrho_{0}}{(n-2) !} \theta^{n-2}(s) p(s) .
\end{aligned}
$$

Integrating this inequality from $s_{2}$ to $s$, we arrive at

$$
\begin{aligned}
c(s) u^{(n-1)}(s) & \leq c\left(s_{2}\right) u^{(n-1)}\left(s_{2}\right)-\frac{\epsilon_{0} \varrho_{0}}{(n-2) !} \int_{s_{2}}^{s} \theta^{n-2}(\xi) p(\xi) \mathrm{d} \xi \\
& \leq-\frac{\epsilon_{0} \varrho_{0}}{(n-2) !} \int_{s_{2}}^{s} \theta^{n-2}(\xi) p(\xi) \mathrm{d} \xi,
\end{aligned}
$$

or

$$
u^{(n-1)}(s) \leq \frac{\epsilon_{0} \varrho_{0}}{(n-2) !} \frac{1}{c(s)} \int_{s_{2}}^{s}\left(\theta^{n-2}(\xi)\right) p(\xi) \mathrm{d} \xi .
$$

By integrating again from $s_{2}$ to $s$, we get

$$
u^{(n-2)}(s) \leq u^{(n-2)}\left(s_{2}\right)-\frac{\epsilon_{0} \varrho_{0}}{(n-2) !} \int_{s_{2}}^{s}\left(\frac{1}{c(z)} \int_{s_{2}}^{z} \theta^{n-2}(\xi) p(\xi) \mathrm{d} \xi\right) \mathrm{d} z
$$


which with (5) gives $\lim _{s \rightarrow \infty} u^{(n-2)}(s)=-\infty$, a contradiction. Therefore, $u^{(n-2)}(s)$ converges to zero.

For $\left(c_{0,3}\right)$ : From the properties of the derivatives in $(\mathrm{C} 1)$, we have that

$$
\lim _{s \rightarrow \infty} u^{(n-2)}(s)-u^{(n-2)}(s)=\int_{s}^{\infty} \frac{c(\xi) u^{(n-1)}(\xi)}{c(\xi)} \mathrm{d} \xi \leq c(s) u^{(n-1)}(s) w_{0}(s),
$$

or equivalently.

$$
u^{(n-2)}(s) \geq-c(s) u^{(n-1)}(s) w_{0}(s) .
$$

Thus, we see that

$$
w_{0}^{2} \frac{\mathrm{d}}{\mathrm{d} s} \frac{u^{(n-2)}(s)}{w_{0}(s)}=w_{0}(s) u^{(n-1)}(s)+c^{-1}(s) u^{(n-2)}(s) \geq 0 .
$$

Lemma 3. Assume that $u \in U^{*}$ which satisfies (C1), and (5) holds. If there exists a $\gamma_{0} \in(0,1)$ such that

$$
p(s) \theta^{n-2}(s) c(s) w_{0}^{2}(s) \geq \frac{(n-2) !}{\epsilon_{0}} \gamma_{0},
$$

for all $\epsilon_{0} \in(0,1)$, then there is $s_{1} \in\left[s_{0}, \infty\right)$ such that

$$
\begin{aligned}
& \left(c_{1,0}\right) \frac{\mathrm{d}}{\mathrm{d} s} \frac{u^{(n-2)}(s)}{w_{0}^{\gamma_{0}}(s)} \leq 0 ; \\
& \left(c_{2,0}\right) \lim _{s \rightarrow \infty} \frac{u^{(n-2)}(s)}{w_{0}^{\gamma_{0}}(s)}=0,
\end{aligned}
$$

for $s \geq s_{1}$.

Proof. Assume that $u \in U^{*}$ which satisfies (C1). From Lemma 2, we have that $\left(c_{0,1}\right)-\left(c_{0,3}\right)$ hold. Performing some simple computation and using $(1),(7),\left(c_{0,1}\right)$ and $\left(c_{0,3}\right)$, we obtain

$$
\begin{aligned}
\left(c(s) u^{(n-1)}(s)\right)^{\prime} & =-p(s) u(\theta(s)) \quad[\operatorname{using}(1)] \\
& \leq-\frac{\epsilon_{0}}{(n-2) !} p(s) \theta^{n-2}(s) u^{(n-2)}(\theta(s)) \quad\left[\operatorname{using}\left(c_{0,1}\right)\right] \\
& \leq-\frac{\gamma_{0}}{c(s) w_{0}^{2}(s)} u^{(n-2)}(s) \quad[\operatorname{using}(7)] .
\end{aligned}
$$

Integrating the above inequality from $s_{1}$ to $s$, we get

$$
\begin{aligned}
c(s) u^{(n-1)}(s) & \leq c\left(s_{1}\right) u^{(n-1)}\left(s_{1}\right)-\gamma_{0} \int_{s_{1}}^{s} \frac{1}{c(\xi) w_{0}^{2}(\xi)} u^{(n-2)}(\xi) \mathrm{d} \xi \\
& \leq c\left(s_{1}\right) u^{(n-1)}\left(s_{1}\right)+\gamma_{0} \frac{u^{(n-2)}(s)}{w_{0}\left(s_{1}\right)}-\gamma_{0} \frac{u^{(n-2)}(s)}{w_{0}(s)} .
\end{aligned}
$$

From $\left(c_{0,2}\right)$, there is a $s_{2} \geq s_{1}$ such that

$$
c\left(s_{1}\right) u^{(n-1)}\left(s_{1}\right)+\gamma_{0} \frac{u^{(n-2)}(s)}{w_{0}\left(s_{1}\right)} \leq 0 \text { for } s \geq s_{2} .
$$

Thus, (10) turn into

$$
w_{0}(s) u^{(n-1)}(s) \leq-\gamma_{0} c^{-1}(s) u^{(n-2)}(s),
$$


which yields

$$
\left(\frac{u^{(n-2)}(s)}{w_{0}^{\gamma_{0}}(s)}\right)^{\prime}=\frac{w_{0}(s) u^{(n-1)}(s)+\gamma_{0} c^{-1}(s) u^{(n-2)}(s)}{w_{0}^{\gamma_{0}+1}(s)} \leq 0 .
$$

Now, from (12), we have $u^{(n-2)}(s) / w_{0}^{\gamma_{0}}(s)$ is positive decreasing. Then,

$$
\lim _{s \rightarrow \infty} u^{(n-2)}(s) / w_{0}^{\gamma_{0}}(s)=k \geq 0
$$

Suppose that $k>0$, and so there is a $s_{2} \geq s_{1}$ with

$$
\frac{u^{(n-2)}(s)}{w_{0}^{\gamma_{0}}(s)} \geq k, \text { for } s \geq s_{2}
$$

We define the function

$$
\xi(s):=\frac{u^{(n-2)}(s)+w_{0}(s) c(s) u^{(n-1)}(s)}{w_{0}^{\gamma_{0}}(s)} .
$$

Then, from $\left(c_{0,3}\right), \xi(s)>0$ for $s \geq s_{1}$. Differentiating $\xi(s)$ and using (9), we get

$$
\begin{aligned}
\xi^{\prime}(s) & =\frac{w_{0}^{\gamma_{0}+1}(s)\left(c(s) u^{(n-1)}(s)\right)^{\prime}+\gamma_{0} u^{(n-2)}(s) c^{-1}(s) w_{0}^{\gamma_{0}-1}(s)+\gamma_{0} w_{0}^{\gamma_{0}}(s) u^{(n-1)}(s)}{w_{0}^{2 \gamma_{0}}(s)} \\
& \leq \frac{\gamma_{0} u^{(n-1)}(s)}{w_{0}^{\gamma_{0}}(s)}
\end{aligned}
$$

Using (11) and (13), $w_{0}(s) u^{(n-1)}(s) \leq-\varrho_{0} \gamma_{0} c^{-1}(s) w_{0}^{\gamma_{0}}(s)$, which with (14) gives $\xi^{\prime}(s) \leq-\varrho_{0} \gamma_{0}^{2}\left(1 /\left(c(s) w_{0}(s)\right)\right)$. Integrating this inequality from $s_{1}$ to $s$, we arrive at

$$
\xi\left(s_{1}\right) \geq \xi\left(s_{1}\right)-\xi(s) \geq \varrho_{0} \gamma_{0}^{2} \ln \frac{w_{0}\left(s_{1}\right)}{w_{0}(s)} \rightarrow \infty \text { as } s \rightarrow \infty,
$$

which is a contradiction. Thus, $u^{(n-2)}(s) / w_{0}^{\gamma_{0}}(s)$ converges to zero.

Lemma 4. Assume that $u \in U^{*}$ which satisfies (C1), and (5) holds. If

$$
\liminf _{s \rightarrow \infty} \frac{w_{0}(\theta(s))}{w_{0}(s)}:=\kappa<\infty,
$$

and there exists an increasing sequence $\left\{\gamma_{r}\right\}_{r=0}^{m}$,

$$
\gamma_{r}:=\gamma_{0} \frac{\kappa^{\gamma_{r-1}}}{1-\gamma_{r-1}}
$$

with $\gamma_{m} \in(0,1)$ and $\gamma_{0}$ satisfies (7), then there is $s_{1} \in\left[s_{0}, \infty\right)$ such that

$$
\begin{aligned}
& \left(c_{1, r}\right) \frac{\mathrm{d}}{\mathrm{d} s} \frac{u^{(n-2)}(s)}{w_{0}^{\gamma_{r}}(s)} \leq 0 ; \\
& \left(c_{2, r}\right) \lim _{s \rightarrow \infty} \frac{u^{(n-2)}(s)}{w_{0}^{\gamma_{r}}(s)}=0,
\end{aligned}
$$

for all $s \geq s_{1}$. 
Proof. Assume that $u \in U^{*}$ which satisfies (C1). From Lemma 2 and Lemma 3, we have that $\left(c_{0,1}\right)-\left(c_{0,3}\right),\left(c_{1,0}\right)$ and $\left(c_{2,0}\right)$ hold. We will prove this lemma by induction. Now, we assume that $\left(c_{1, r}\right)$ and $\left(c_{2, r}\right)$ hold for $r>0$. Proceeding as in the proof of Lemma 3 , we arrive at (8) holds. Using $\left(c_{1, r}\right)$, (8) becomes

$$
\left(c(s) u^{(n-1)}(s)\right)^{\prime} \leq-\frac{\epsilon_{0}}{(n-2) !} p(s) \theta^{n-2}(s) \frac{w_{0}^{\gamma_{r}}(\theta(s))}{w_{0}^{\gamma_{r}}(s)} u^{(n-2)}(s) .
$$

Integrating this inequality from $s_{1}$ to $s$, we find

$$
\begin{aligned}
c(s) u^{(n-1)}(s) \leq & c\left(s_{1}\right) u^{(n-1)}\left(s_{1}\right) \\
& -\frac{\epsilon_{0}}{(n-2) !} \int_{s_{1}}^{s} p(\xi) \theta^{n-2}(\xi) \frac{w_{0}^{\gamma_{r}}(\theta(\xi))}{w_{0}^{\gamma_{r}}(\xi)} u^{(n-2)}(\xi) \mathrm{d} \xi \\
\leq & c\left(s_{1}\right) u^{(n-1)}\left(s_{1}\right) \\
& -\frac{\epsilon_{0}}{(n-2) !} \frac{u^{(n-2)}(s)}{w_{0}^{\gamma_{r}}(s)} \int_{s_{1}}^{s} w_{0}^{\gamma_{r}-1}(\xi) p(\xi) \theta^{n-2}(\xi) \frac{w_{0}^{\gamma_{r}}(\theta(\xi))}{w_{0}^{\gamma_{r}}(\xi)} \mathrm{d} \xi,
\end{aligned}
$$

which with (7) and (15) gives

$$
\begin{aligned}
c(s) u^{(n-1)}(s) & \leq c\left(s_{1}\right) u^{(n-1)}\left(s_{1}\right)-\gamma_{0} \kappa^{\gamma_{r}} \frac{u^{(n-2)}(s)}{w_{0}^{\gamma_{r}}(s)} \int_{s_{1}}^{s} \frac{w_{0}^{\gamma_{r}-2}(\xi)}{c(\xi)} \mathrm{d} \xi \\
& \leq c\left(s_{1}\right) u^{(n-1)}\left(s_{1}\right)+\frac{\gamma_{0} \kappa^{\gamma_{r}}}{1-\gamma_{r}} \frac{u^{(n-2)}(s)}{w_{0}^{\gamma_{r}}(s)} w_{0}^{\gamma_{r}-1}\left(s_{1}\right)-\frac{\gamma_{0} \kappa^{\gamma_{r}}}{1-\gamma_{r}} \frac{u^{(n-2)}(s)}{w_{0}(s)} .
\end{aligned}
$$

Thus, using the fact that $\lim _{s \rightarrow \infty} u^{(n-2)}(s) / w_{0}^{\gamma_{r}}(s)=0$, we find

$$
c\left(s_{1}\right) u^{(n-1)}\left(s_{1}\right)+\frac{\gamma_{0} \kappa^{\gamma_{r}}}{1-\gamma_{r}} \frac{u^{(n-2)}(s)}{w_{0}^{\gamma_{r}}(s)} w_{0}^{\gamma_{r}-1}\left(s_{1}\right) \leq 0,
$$

eventually, and then

$$
c(s) u^{(n-1)}(s) \leq-\gamma_{r+1} \frac{u^{(n-2)}(s)}{w_{0}(s)} .
$$

Therefore,

$$
\left(\frac{u^{(n-2)}(s)}{w_{0}^{\gamma_{r+1}}(s)}\right)^{\prime}=\frac{w_{0}(s) u^{(n-1)}(s)+\gamma_{r+1} c^{-1}(s) u^{(n-2)}(s)}{w_{0}^{\gamma_{r+1}+1}(s)} \leq 0 .
$$

Now, we have that $u^{(n-2)} / w_{0}^{\gamma_{r+1}}$ is a positive decreasing function. Then,

$$
\lim _{s \rightarrow \infty} u^{(n-2)}(s) / w_{0}^{\gamma_{r+1}}(s)=h \geq 0 .
$$

Assume that $h>0$. Hence, $u^{(n-2)}(s) / w_{0}^{\gamma_{r+1}}(s)>h$ for all $s \geq s_{2}$ for some $s_{2} \geq s_{1}$. Replacing $\gamma_{0}$ with $\gamma_{r+1}$, and proceeding as in the proof of $\left(c_{2,0}\right)$, we can verify that $\left(c_{2, r+1}\right)$ holds.

Theorem 1. Assume that (5), (15),

$$
\liminf _{s \rightarrow \infty} \int_{\theta(s)}^{s} p(\xi) \frac{\theta^{n-1}(\xi)}{c(\theta(\xi))} \mathrm{d} \xi>\frac{(n-1) !}{\mathrm{e}},
$$

and

$$
\limsup _{s \rightarrow \infty} \int_{s_{0}}^{s}\left(p(\xi) R(\xi)-\frac{\left(R^{\prime}(\xi)\right)^{2}}{R(\xi) R_{1}(\xi)}\right) d \xi=\infty
$$


where

$$
\begin{aligned}
R(s) & =\frac{1}{(n-3) !} \int_{s}^{\infty}(\xi-l)^{n-3} w_{0}(\xi) \mathrm{d} \xi \\
R_{1}(s) & =\frac{1}{(n-4) !} \int_{s}^{\infty}(\xi-l)^{n-4} w_{0}(\xi) \mathrm{d} \xi
\end{aligned}
$$

If there exists a $\gamma_{0} \in(0,1)$ satisfies ( 7$)$ and

$$
\liminf _{s \rightarrow \infty} \int_{\theta(s)}^{s} p(\xi) w_{0}(\xi) \theta^{n-2}(\xi) \mathrm{d} \xi>(n-2) ! \frac{1-\gamma_{m}}{\epsilon_{0} \mathrm{e}},
$$

then every solution of (1) is oscillatory, where $\gamma_{m}<1$ is defined as in Lemma 4.

Proof. Assume the contrary that $\psi \in U^{*}$. Then, from Lemma 2.2.1 [24], we have the following three cases, eventually:
(a) $u^{(j)}(s)>0$ for $j=0,1, n-1$ and $u^{(n)}(s)<0$;
(b) $u^{(j)}(s)>0$ for $j=0,1, n-2$ and $u^{(n-1)}(s)<0$;
(c) $(-1)^{j} u^{(j)}(s)>0$ for $j=0,1, \ldots, n-1$.

From [17] (Theorem 2.1), the conditions (16) and (17) rule out the cases (a) and (c), respectively.

Then, we have (b) holds. From Lemma 4, we have that $\left(c_{1, m}\right)$ and $\left(c_{2, m}\right)$ hold. Now, we define

$$
M(s)=c u^{(n-1)}(s) w_{0}(s)+u^{(n-2)}(s) .
$$

Then, from $\left(c_{0,3}\right), M(s)>0$ for $s \geq s_{2}$, and

$$
M^{\prime}(s)=\left(c u^{(n-1)}(s)\right)^{\prime} w_{0}(s),
$$

and so

$$
M^{\prime}(s)=\left(c u^{(n-1)}(s)\right)^{\prime} w_{0}(s) \leq-p(s) w_{0}(s) u(\theta(s)) .
$$

From $\left(c_{1, m}\right)$ and (19), we get

$$
M(s) \leq\left(1-\gamma_{m}\right) u^{(n-2)}(s) .
$$

Using $\left(c_{0,1}\right)$, we have

$$
M(s) \leq\left(1-\gamma_{m}\right) u^{(n-2)}(s) \leq\left(1-\gamma_{m}\right) \frac{(n-2) !}{\epsilon_{0} s^{n-2}} u(s) .
$$

Thus, (20) becomes

$$
M^{\prime}(s)+p(s) w_{0}(s) \frac{\epsilon_{0} \theta^{n-2}(s)}{(n-2) !\left(1-\gamma_{m}\right)} M(\theta(s)) \leq 0 .
$$

Hence, $M$ is a positive solution of the differential inequality (21). Using Theorem 1 in [25], the equation

$$
M^{\prime}(s)+p(s) w_{0}(s) \frac{\epsilon_{0} \theta^{n-2}(s)}{(n-2) !\left(1-\gamma_{m}\right)} M(\theta(s))=0
$$

has also a positive solution. However, from Theorem 2 in [26] that condition (18) implies oscillation of (22), a contradiction. 
Example 1. Consider the DDE of Euler type

$$
\left(s^{4} u^{\prime \prime \prime}(s)\right)^{\prime}+p_{0} u\left(\theta_{0} s\right)=0,
$$

where $s \geq 1, \theta_{0} \in(0,1)$ and $p_{0}<18 / \theta_{0}$. Then, we conclude that

$$
w_{0}(s)=\frac{1}{3 s^{3}}, w_{1}(s)=\frac{1}{6 s^{2}}, w_{2}(s)=\frac{1}{6 s},
$$

and so (5) holds. Now, conditions (16) and (17) reduce to

$$
p_{0} \ln \frac{1}{\theta_{0}}>\frac{6 \theta_{0}}{\mathrm{e}},
$$

and $p_{0}>6$. By choosing $\gamma_{0}=\frac{1}{18} \theta_{0} p_{0}<1$, we obtain that (7) holds, and (18) becomes

$$
p_{0} \ln \frac{1}{\theta_{0}}<\frac{1}{3 \mathrm{e} \theta_{0}^{2}}\left(18-\theta_{0} p_{0}\right)
$$

Using Theorem 1, equation (23) is oscillatory if

$$
p_{0}>\max \left\{6, \frac{6 \theta_{0}}{\mathrm{e} \ln \left(1 / \theta_{0}\right)}, \frac{18}{\theta_{0}+3 \theta_{0}^{2} \mathrm{e} \ln \left(1 / \theta_{0}\right)}\right\} \text {. }
$$

Remark 1. In particular, consider the DDE $\left(s^{4} u^{\prime \prime \prime}(s)\right)^{\prime}+p_{0} u(s / 2)=0$. To the best of our knowledge, the results in $[17,18]$ provide the sharp criterion for the oscillation of this equation, which is $p_{0}>18$. However, the condition (24) provides a sharper result, $p_{0}>9.4087$.

\section{Conclusions}

A new criterion of oscillation of a class of even-order delay differential equations is established. The approach used is based on improving the asymptotic properties of the positive solutions of the studied equation. The new criterion inferred provides more sharp results compared to the related results in the literature. It is interesting to extend the results obtained on the neutral delay differential equations.

Author Contributions: Conceptualization, O.M., C.C. and S.A.; Data curation, O.M., C.C. and S.A.; Formal analysis, O.M., C.C. and S.A.; Investigation, O.M. and S.A.; Methodology, O.M., C.C. and S.A. All authors have read and agreed to the published version of the manuscript.

Funding: This research was funded by Supporting Project number (RSP-2021/167), King Saud University, Riyadh, Saudi Arabia.

Institutional Review Board Statement: Not applicable.

Informed Consent Statement: Not applicable.

Data Availability Statement: Not applicable.

Conflicts of Interest: The authors declare no conflict of interest.

\section{References}

1. Norkin, S.B. Second Order Differential Equations with Retarded Argument; Nauk: Moscow, Russia, 1965. (In Russian)

2. Rihan, F.A. Delay Differential Equations and Applications to Biology; Springer Nature: Singapore, 2021.

3. Ali, B.; Abbas, M. Existence and stability of fixed point set of Suzuki-type contractive multivalued operators in b-metric spaces with applications in delay differential equations. J. Fixed Point Theory Appl. 2017, 19, 2327-2347. [CrossRef]

4. Baculíková, B. Oscillatory behavior of the second order noncanonical differential equations. Electron. J. Qual. Theory Differ. Equ. 2019, 89, 1-11. [CrossRef]

5. Chatzarakis, G.E.; Moaaz, O.; Li, T.; Qaraad, B. Some oscillation theorems for nonlinear second-order differential equations with an advanced argument. Adv. Differ. Equ. 2020, 2020, 160. [CrossRef] 
6. Džurina, J.; Jadlovská, I. A note on oscillation of second-order delay differential equations. Appl. Math. Lett. 2017,69 126-132. [CrossRef]

7. Džurina, J.; Jadlovská, I. Oscillatory results for second-order noncanonical delay differential equations. Opuscula Math. 2019, 39, 483-495. [CrossRef]

8. Bohner, M.; Jadlovská, I.; Grace, S. R. Oscillation criteria for second-order neutral delay differential equations. Electron. J. Qual. Theory Differ. Equ. 2017, 60, 1-12. [CrossRef]

9. Moaaz, O.; Anis, M.; Baleanu, D., Muhib, A. More effective criteria for oscillation of second-order differential equations with neutral arguments. Mathematics 2020, 8, 986. [CrossRef]

10. Moaaz, O.; Elabbasy, E.M.; Qaraad, B. An improved approach for studying oscillation of generalized Emden-Fowler neutral differential equation. J. Ineq. Appl. 2020, 2020, 69. [CrossRef]

11. Bartušek, M.; Cecchi, M.; Došlá, Z.; Marini, M. Fourth-order differential equation with deviating argument. Abstr. Appl. Anal. 2012, 2012, 185242. [CrossRef]

12. Agarwal, R.P.; Bohner, M.; Li, T.; Zhang, C. A new approach in the study of oscillatory behavior of even-order neutral delay differential equations. Appl. Math. Comput. 2013, 225, 787-794. [CrossRef]

13. Bazighifan, O.; El-Nabulsi, R.A.; Moaaz, O. Asymptotic properties of neutral differential equations with variable coefficients. Axioms 2020, 9, 96. [CrossRef]

14. Moaaz, O.; Kumam, P.; Bazighifan, O. On the oscillatory behavior of a class of fourth-order nonlinear differential equation. Symmetry 2020, 12, 524. [CrossRef]

15. Baculíková, B.; Džurina, J.; Graef, J.R. On the oscillation of higher-order delay differential equations. J. Math. Sci. 2012, 187, 387-400. [CrossRef]

16. Zhang, C.; Li, T.; Suna, B.; Thandapani, E. On the oscillation of higher-order half-linear delay differential equations. Appl. Math Lett. 2011, 24, 1618-1621. [CrossRef]

17. Zhang, C.; Agarwal, R.P.; Bohner, M.; Li, T. New results for oscillatory behavior of even-order half-linear delay differential equations. Appl. Math. Lett. 2013, 26, 179-183. [CrossRef]

18. Moaaz, O.; Muhib, A. New oscillation criteria for nonlinear delay differential equations of fourth-order. Appl. Math. Comput. 2020, 377, 125192. [CrossRef]

19. Dzurina, J.; Grace, S.R.; Jadlovska, I. On nonexistence of Kneser solutions of third-order neutral delay differential equations. Appl. Math. Lett. 2019, 88, 193-200. [CrossRef]

20. Graef, J.R.; Jadlovská, I.; Tunç, E. Sharp asymptotic results for third-order linear delay differential equations. J. Appl. Analy. Comput. 2021, 11, 2459-2472. [CrossRef]

21. Jadlovská, I.; Chatzarakis, G.E.; Džurina, J.; Grace, S.R. On sharp oscillation criteria for general third-order delay differential equations. Mathematics 2021, 9, 1675. [CrossRef]

22. Moaaz, O.; Baleanu, D.; Muhib, A. New aspects for non-existence of Kneser solutions of neutral differential equations with odd-order. Mathematics 2020, 8, 494. [CrossRef]

23. Moaaz, O.; Chalishajar, D.; Bazighifan, O. Asymptotic behavior of solutions of the third order nonlinear mixed type neutral differential equations. Mathematics 2020, 8, 485. [CrossRef]

24. Agarwal, R.P.; Grace, S.R.; O’Regan, D. Oscillation Theory for Difference and Functional Differential Equations; Kluwer Academic Publishers: Dordrecht, The Netherlands, 2000.

25. Philos, C.G. On the existence of nonoscillatory solutions tending to zero at $\infty$ for dif ferential equations with positive delays. Arch. Math. 1981, 36, 168-178. [CrossRef]

26. Kitamura, Y.; Kusano, T. Oscillation of first-order nonlinear differential equations with deviating arguments. Proc. Amer. Math. Soc. 1980, 78, 64-68. [CrossRef] 